Egyptian Journal of Aquatic Biology \& Fisheries

Zoology Department, Faculty of Science,

Ain Shams University, Cairo, Egypt.

ISSN $1110-6131$

Vol. 25(2): $205-214$ (2021)

www.ejabf.journals.ekb.eg

\title{
Genotypic Detection of Fish-Borne Zoonotic Trematodes Using the Hotshot DNA
}

\section{Extraction Method}

\author{
Ahmed H. Elaswad ${ }^{1}$, Eman M. Abouelhassan ${ }^{2 *}$ Hanaa M. Fadel $^{3}$ \\ ${ }^{1}$ Department of Animal Wealth Development, Faculty of Veterinary Medicine, Suez Canal \\ University, Ismailia 41522, Egypt. \\ ${ }^{2}$ Department of Veterinary Parasitology, Faculty of Veterinary Medicine, Suez Canal University, \\ Ismailia 41522, Egypt. \\ ${ }^{3}$ Department of Animal Hygiene and Zoonoses, Faculty of Veterinary Medicine, Suez Canal \\ University, Ismailia 41522, Egypt. \\ *Corresponding Author: eman_abouelhassan@vet.suez.edu.eg
}

ARTICLE INFO Article History:

Received: Jan. 17, 2021

Accepted: March 22, 2021

Online: April 6, 2021

Keywords:

Hotshot method,

DNA extraction,

Trematodes,

Molecular identification,

Morphological

\begin{abstract}
Efficient DNA extraction is a keystone in molecular assays. A wide range of methods is used to extract DNA from biological materials. These methods vary in their efficiency, economic costs, and availability. Therefore, the present study was conducted to assess the efficiency of a Hotshot method for DNA extraction from minute fish trematodes in comparison to a commercial kit. A total of 68 samples were examined. Samples included 29 encysted metacercariae from the African catfish (Clarias gariepinus) collected from the Nile tributaries in Ismailia Governorate, and 39 adult trematodes collected from rats after being experimentally infected with encysted metacercariae from fish samples. Helminths were morphologically identified where they belonged to family Cyathocotylidae, species Mesostephanus burmanicus, Prohemistomum vivax, and Mesostephanus appendiculatus. The DNA yield by the Hotshot method was compared to the commercial kit. Hotshot method produced $28 \%$ higher DNA yield per sample (mean \pm SE: $2.65 \pm 0.83 \mu \mathrm{g}$ ) than the commercial kit $(2.07 \pm$ $0.16 \mu \mathrm{g}$ ), but the difference was not significant (Mann-Whitney $\mathrm{U}$ test, $\mathrm{P}>0.05$ ). PCR amplification success of the internal transcribed spacer 2 (ITS-2) was also higher for trematode samples extracted by the Hotshot method than the commercial kit. Although the differences were not statistically significant, the Hotshot method is still rapid, cheap, and does not require special reagents or equipments for DNA extraction from minute helminths.
\end{abstract}

\section{INTRODUCTION}

Parasites are responsible for significant harmful effects on hosts which may end with death in addition to the economic losses (Borgsteede, 1996). Food-borne parasitic infestation has been recognized as an important public health problem. For instance, in Egypt, freshwater fishes are considered an important source of parasitic infestation to humans and fish-eating mammals especially with the pollution problem of the rivers and lakes (Mohamed, 1996). One of the emerging infectious diseases is fish-borne zoonotic trematodes. Fish-borne zoonotic trematodes are divided into two groups, the small liver 
flukes, and the minute intestinal flukes. Fifty-nine trematode species are zoonotic to humans, infecting more than 18 million people worldwide (WHO, 1995; Keiser \& Utzinger, 2009; Fadel et al., 2019).

Fish are considered not only a final host but also an intermediate host for the larval stages of many parasites such as the encysted metacercariae of different species of trematodes (Abou-Eisha $\boldsymbol{e t}$ al., 2008) The diagnosis of trematode parasites depends on morphological and molecular identification. Morphological identification requires experience and special sample preservation and treatment. Whereas, molecular identification provides an alternative to overcome the limitations of morphological identification (Abouelhassan et al., 2019).

Although molecular identification is more specific, rapid, and sensitive, it is difficult to obtain sufficient and PCR-grade DNA from some parasites such as minute helminths or their larval stages (Gasser, 1993). In the current methods, some of the DNA may be lost during the extraction. In addition, the lack of genetic information or genome sequences of many species of parasites limits the study of such parasites at the molecular level (Geracia et al., 2007).

Therefore, the objectives of this study were determined to assess the efficiency of a Hotshot DNA extraction technique for minute single worms and their larval stages to overcome the limitations of other DNA extraction methods, improve the yield of DNA for PCR, and investigate whether DNA extracted by this method is of sufficient quality for PCR and sequencing or not.

\section{MATERIALS AND METHODS}

\section{Sample collection}

A total of 68 parasite samples were examined. The samples included 29 encysted metacercariae from the African catfish, Clarias gariepinus, collected from the Nile tributaries in Ismailia governorate from September 2017 to April 2018, in addition to 39 adult trematodes collected from rats after being experimentally infected with encysted metacercariae. Fish samples were collected, placed in a container with aerated water, and immediately transported to the lab for examination.

\section{Detection of encysted metacercariae}

Gills, musculature, and internal organs of fish were grossly examined to detect any abnormalities using a magnifying hand lens (Mahdy et al., 1995). Microscopically, a few drops of saline solution $(0.9 \% \mathrm{NaCl})$ were added to a small piece from each grossly examined part, and then tissue samples were compressed between two glass slides and examined for the presence of encysted metacercariae (Morishita et al., 1965; Schaperclaus et al., 1992; Fadel et al., 2019). The detected encysted metacercariae were individually removed and randomly divided into three groupsas follows: the first group was utilized in the experimental infection of rats while the second and the third groups were preserved in absolute ethanol until DNA extraction with the two methods (Table1).

\section{Experimental infection:}

Ten three weeks-old rats were divided into two groups (5 in each group). The feces of rats were examined before the experimental infection to ensure that they were parasite free. The first group was fed on encysted metacercariae isolated from Clarias gariepinus, while the second group was the negative control. Fecal samples from the two groups were 
inspected daily for the presence of eggs by the direct examination technique. Infected animals were sacrificed, and the contents of the small intestine were evacuated and examined under a stereomicroscope for the presence of any trematodes. The detected trematodes were collected in normal saline and randomly divided into two groups; each containing the same species of trematode helminths. One group was used for parasitological examination, while the second group was preserved in absolute ethanol until DNA extraction.

\section{Parasitological examination}

\section{Morphological identification of adult worms}

The collected worms were washed in saline, fixed in cold AFA (alcohol-formalinacetic acid) ( Georgi \& Georgi, 1992), stained with alum carmine, dehydrated, and then cleaned in xylene, mounted in Canada balsam (Abou Zaid $\boldsymbol{e t}$ al., 2018), then examined and identified microscopically as adult trematodes.

\section{Molecular identification}

\section{DNA Extraction}

Following morphological identification, the DNA of trematodes and encysted metacercariae was extracted with the two methods; the Hotshot and the kit-based methods. Each sample contained either a single worm or single metacercaria (Table 1).

\section{The kit-based DNA Extraction}

DNA was extracted from the samples using the Genomic DNA Purification kit (Applied Biotechnology Co. Ltd, Egypt) following the manufacturer's recommendations. Briefly, the samples were incubated for 20 minutes at $65^{\circ} \mathrm{C}$ in $200 \mu \mathrm{l}$ of Nuclei Lysis Solution, plus $40 \mu \mathrm{l}$ of a $20-\mathrm{mg} / \mathrm{ml}$ Proteinase $\mathrm{K}$ solution. The tubes were then centrifuged at $10,000 \times g$ to eliminate debris. Supernatants were collected and $100 \mu \mathrm{l}$ of isopropanol were added to each sample and mixed. The mixture was run through filter columns at $13,000 \times g$ for 1 minute. DNA, bound to the filter, was washed and eluted in 50 $\mu 1 \mathrm{TE}$ buffer.

\section{The modified Hotshot method}

DNA was extracted from the samples using the modified Hotshot method following the steps of Meeker et al. (2018). The Hotshot method was slightly modified to account for the differences in sample types used in the current study. Briefly, single worms or single metacercariae were placed into $0.2 \mathrm{ml}$ PCR tubes containing $20-25 \mu 1$ of $50 \mathrm{mM}$ $\mathrm{NaOH}$ so that the worm would completely be submerged in the solution. The samples were then heated to $95^{\circ} \mathrm{C}$ in a thermal cycler for 10-20 min until the tissue was friable. The tubes were cooled to $4^{\circ} \mathrm{C}$ before adding 1/10th volume of $1 \mathrm{M}$ Tris- $\mathrm{HCl}(\mathrm{pH} \mathrm{8.0)}$ ) to neutralize the basic solution. The samples were centrifuged to pellet the debris, and the supernatant was immediately used for PCR.

The concentration and purity of the extracted DNA by the two methods were measured using a NanoDrop spectrophotometer and stored at $-20^{\circ} \mathrm{C}$ until use.

\section{Amplification of the ITS-2 gene}

Five $\mu l$ of the DNA solution were used per $50 \mu \mathrm{PCR}$ reaction. The PCR was conducted according to Arya $\boldsymbol{e t}$ al. (2016). Primers targeting the ITS-2 region were used: AP102 F 5' AGAGCGCAGCCAACTGTGTGA 3' and AP102 R 5' TGCCACGTCCTAGCATCAGCC 3'. The PCR was performed in a thermal cycler (Techne, UK). The amplification of a 369-bp product of the ITS-2 region was achieved at the following conditions: initial denaturation for $5 \mathrm{~min}$ at $94^{\circ} \mathrm{C}$, followed by 35 cycles of 
denaturation for $30 \mathrm{~s}$ at $94^{\circ} \mathrm{C}$, annealing for $38 \mathrm{~s}$ at $57^{\circ} \mathrm{C}$, and extension at $72^{\circ} \mathrm{C}$ for $42 \mathrm{~s}$, and a final extension at $72^{\circ} \mathrm{C}$ for $7 \mathrm{~min}$. After amplification, 8 microliters of the PCR products were loaded in $1.5 \%$ agarose gel prestained with ethidium bromide, electrophoresed for 45 minutes, and visualized by a UV transilluminator.

\section{Sequencing and sequence analysis}

The amplified PCR products showed single clear bands on the gel. Bands were excised from the gel, purified, and sent for sequencing. Sanger sequencing was performed by SolgentCo. Ltd (South Korea). DNA sequence files were visualized and checked for quality in Chromas 2.6.6 (Technelysium Pty Ltd, Queensland, Australia). Sequences were then analyzed using BLAST® (Johnson et al., 2008).

\section{Phylogenetic analysis}

Phylogenetic analysis was performed based on the ITS-2 sequences from several closely related fish trematode species. A phylogenetic tree was constructed in MEGAX (Kumar et al., 2018) using the maximum-likelihood method. In addition, Tamura-Nei model (Tamura and Nei, 1993) was performed, and 1000 bootstrap replicates were organized. The tree was rooted on the midpoint.

\section{Statistical analysis}

The total DNA yield from each method was calculated as follows.

$$
\text { TotalDNAyield }(\mu g)=\frac{\text { DNAconcentration }(n g / \mu l) \times \text { totalvolume }(\mu l)}{1000}
$$

As the normality assumption was not satisfied, the non-parametric Mann-Whitney U test was used to compare the total DNA yield of the two methods. The statistical analysis was performed in IBM SPSS for Windows, version 20.0 (IBM Corp., Armonk, NY, USA).

\section{Ethical approval}

All experiments were conducted in accordance with the Guide for the Care and Use of Laboratory Animals, Faculty of Veterinary Medicine, Suez Canal University, Egypt and the international guidelines for animal experimentation.

\section{RESULTS}

1. Morphological description of the collected parasites family Cyathocotylidae (Poche, 1926)

Based on the morphological identification, the helminths belong to the family Cyathocotylidae, species (Mesostephanus burmanicus, Prohemistomum vivax, and Mesostephanus appendiculatus) (Fig. 1)

\section{Morphological description of Mesostephanus burmanicus.}

The worm is elongated with a caudal appendage. The tegument is covered with spines with many spines present anteriorly. The worm has a subterminal oral sucker and an unconspicuous ventral sucker. The prepharynx is absent, the pharynx is welldeveloped, and the worms have simple intestinal caeca. The testes are ovoid, smooth, oblique in position, and located in the posterior half of the body. Both the cirrus pouch and uterus are well-developed. Folliculated vitellaria are fairly large, forming two lateral curves around the gonads (Fig. 1A). 


\section{Morphological description of Prohemistomum vivax.}

The wormis pyriform in shape, wide in the middle, and attenuated anteriorly and posteriorly. A deep ventral pouch exists in the middle of the fresh specimens. The oral sucker is subterminal leading to a well-developed pharynx. The short esophagus is bifurcated away from acetabulum into intestinal caeca. Acetabulum is ill-developed and spherical in shape. The first testis is ovoid and smooth, while the second one is quadrilateral and tandem in position. The ovary is nearly pyramidal in shape, situated between the two testes. The cirrus pouch is well-developed and located lateral in the left side of the caudal region. The vitelline follicles are fairly large and confined in a horseshoe manner postacetabular around the gonads. The uterus is slightly large, extending from the middle of the fluke till the common genital pore, and contains large operculated oval egg that is yellow in color and thin shelled (Fig.1B).

Morphological description of Mesostephanus appendiculatus.

$M$. appendiculatus has elongated body that is broader posteriorly with a caudal appendage. It is covered with spines that decrease posteriorly. The oral sucker is subterminal. The prepharynx is absent while the pharynx is well-developed and muscular. The esophagus is short and the intestine bifurcates away from the ventral sucker. The intestinal caeca are simple and hidden by the vitelline follicles. The tribocytic organ is illdeveloped. The testes are irregular, triangular in shape, tandem in position, The uterine eggs are thin-shelled, yellow in color, and few in number (Fig. 1C).

\section{Molecular identification}

\section{DNA yield and PCR amplification success}

A total of 68 adult and encysted metacercaria samples were analyzed by the two methods of DNA extraction (Table 1), 38 samples with the DNA extraction kit and 30 with the modified Hotshot method. The average DNA yield from the Hotshot method $(2.65 \pm 0.83 \mu \mathrm{g})$ was $28 \%$ higher than the DNA extraction kit $(2.07 \pm 0.16 \mu \mathrm{g})$, but the difference between the two methods was not significant (Mann-Whitney U test, P>0.05). Thirteen samples $(43 \%)$ extracted by the Hotshot method were successfully amplified in PCR, while 14 samples (36.8) extracted by the kit were amplified.

\section{Sequence analysis}

The DNA sequences were queried in GenBank and identified based on the ITS-2 gene as family Cyathocotylidae with $99 \%$ identity. This family contained several species with identical sequences; therefore, it was difficult to specify the species. The sequence was submitted to the GeneBank (Accession No. MT710952).

\section{Phylogenetic analysis}

The phylogenetic analysis revealed the closest relationship between the sequences obtained in the current study and both Holostephanus dubinini and Cyathocotyle sp. as they clustered together. The second closer cluster contained 10 helminth species including Uvulifer spinatus, Mesostephanus sp., Bolbophorus damnificus, Diplostomum huronense, Diplostomum baeri, Diplostomum pseudospathaceum, Tylodelphys clavate, Austrodiplostomum compactum, and Austrodiplostomum ostrowskiae. The rest of the helminths (9 species) clustered together far from our sequences (Fig. 2). 
Table 1. Results of PCR amplification of partial internal transcribed spacer 2 gene from adult trematodes and encysted metacercariae using DNA extracted by the commercial kit and HotShot method

\begin{tabular}{|c|c|c|c|c|c|c|c|c|c|c|c|}
\hline \multirow[t]{2}{*}{ Method } & \multirow{2}{*}{$\begin{array}{l}\text { Total } \\
\text { no. of } \\
\text { samples }\end{array}$} & \multicolumn{2}{|c|}{ DNA yield $(\mu \mathrm{g})$} & \multicolumn{2}{|c|}{$\begin{array}{l}\text { Amplified } \\
\text { samples }\end{array}$} & \multicolumn{3}{|c|}{ Adult trematodes } & \multicolumn{3}{|c|}{ Encysted metacercaria } \\
\hline & & Mean & $\begin{array}{l}\text { Standard } \\
\text { error }\end{array}$ & No. & $\%$ & $\begin{array}{l}\text { Total } \\
\text { no. }\end{array}$ & Amplified & $\%$ & $\begin{array}{l}\text { Total } \\
\text { no. }\end{array}$ & Amplified & $\%$ \\
\hline $\begin{array}{l}\text { DNA } \\
\text { extraction } \\
\text { kit }\end{array}$ & 38 & 2.07 & 0.16 & 14 & 36.8 & 21 & 7 & 33.3 & 17 & 7 & 41 \\
\hline $\begin{array}{l}\text { HotShot } \\
\text { method }\end{array}$ & 30 & 2.65 & 0.83 & 13 & 43.0 & 18 & 8 & 44.4 & 12 & 5 & 41 \\
\hline
\end{tabular}
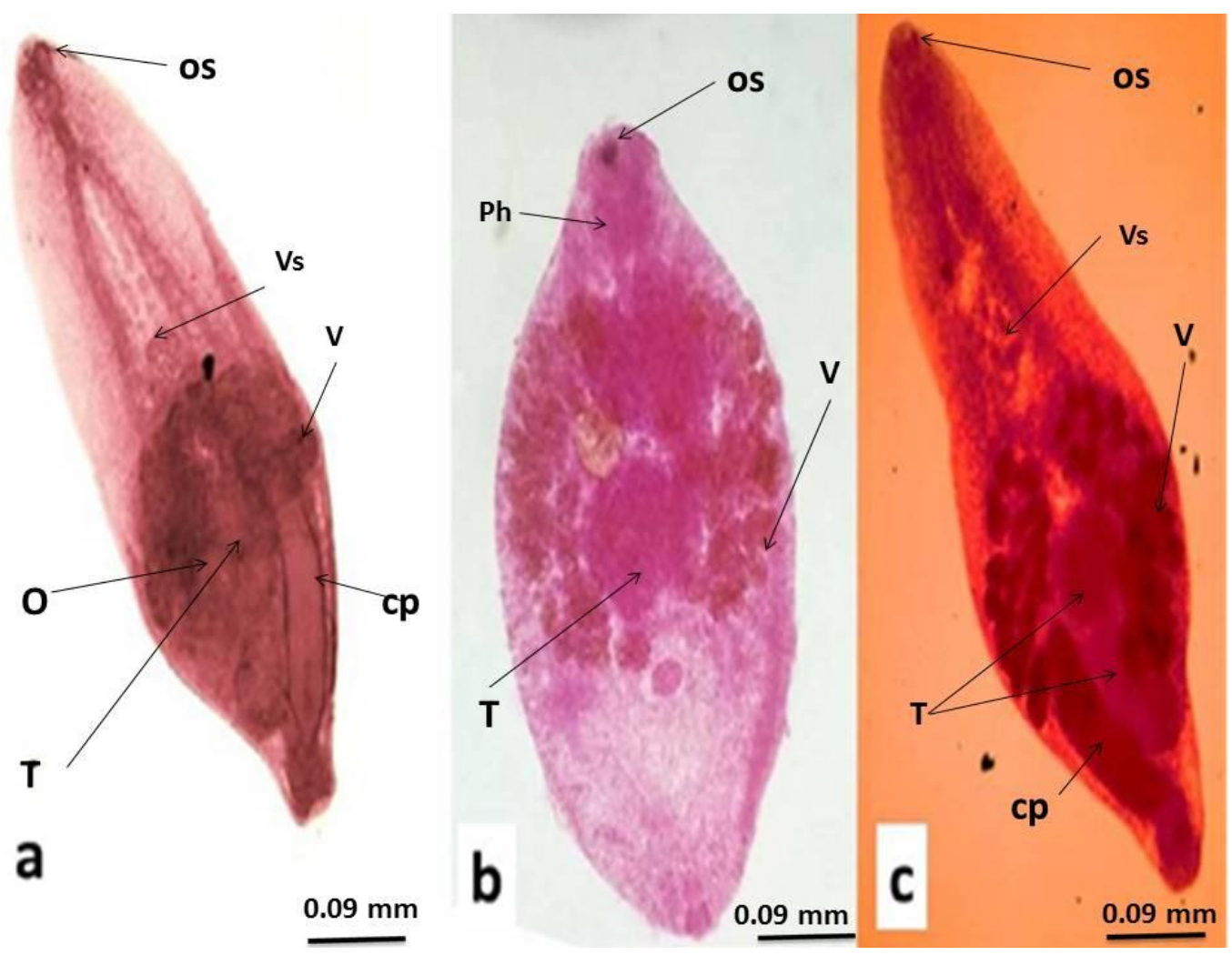

Fig. 1: Light microscopy (LM) of permanent preparation of a. Mesostephanus burmanicus. b. Prohemistomum vivax. c. Mesostephanus appendiculatus.

O: Ovary, O.S.: Oral Sucker, T:Testis, V.S.:Ventral sucker, Ph: Pharynx, $\mathbf{V}$ : vitelline gland, cp: cirrus pouch. 


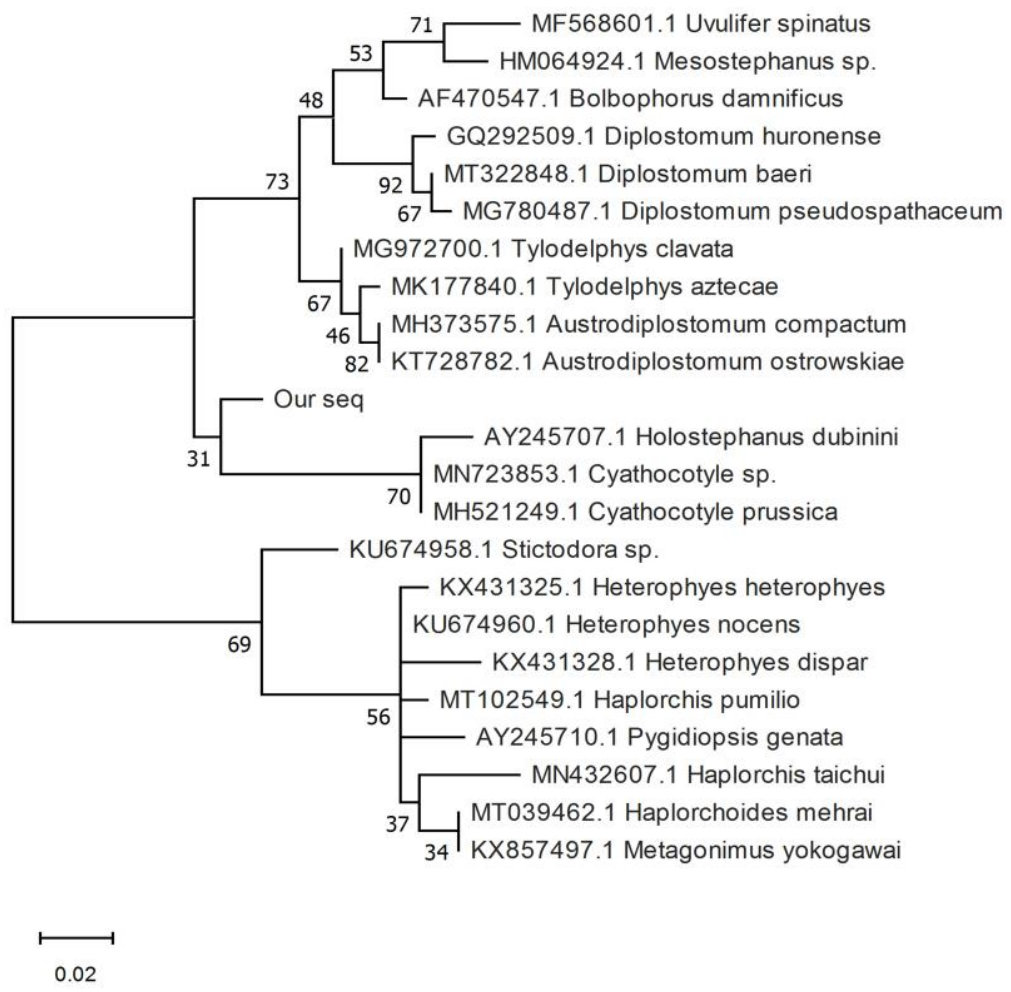

Fig. 2: Phylogenetic tree based on internal transcribed spacer 2 ITS2sequences from 23 parasite species including sequences obtained in the current study (Our seq). The numbers above the branches represent the percentage of replicate trees in which the associated parasites clustered together in the bootstrap test. Bootstrap values less than 50 are not shown. The tree is midpoint rooted.

\section{DISCUSSION}

In the current study, the Hotshot method was modified to extract DNA from minute helminths and their encysted metacercariae. The Hotshot method produced more DNA yield, and the extracted DNA was PCR amplified successfully compared to the commercial kit, but the difference was not statistically significant. The amplified PCR product was successfully sequenced, and the sequence analysis revealed the close relationship between the helminths studied and members of the family Cyathocotylidae.

Morphological identification of parasites requires experience and effort. Physical damage or loss of any part of the samples that is essential for identification may lead to incorrect identification. Also, identification of the parasite eggs and the larval stages is difficult and needs special identification keys and specific treatments (Abouelhassan et al., 2019). Chuboon and Chalobol (2009) affirmed the difficulty to differentiate parasite species by examining the eggs and larval stages using standard methods. Therefore, developing specific and accurate DNA-based methods of parasite identification is required to support morphological identification. Currently, molecular identification using PCR have been developed for different species of parasites (Chuboon \& Chalobol, 
2009). Besides, the use of molecular techniques for identification has been more common to overcome the limitations of morphological identification (Abouelhassan et al., 2019).

In the present study, the samples were morphologically identified as Mesostephanus burmanicus, Prohemistomum vivax and Mesostephanus appendiculatus, all belonged to the family Cyathocotylidae. On the other hand, molecular identification and the sequencing analysis assigned the worms to the family Cyathocotylidae. Despite the accuracy of molecular identification, there is a need for molecular analysis using more than one genetic marker, or accompanying molecular analysis with the morphological characteristics for species identification. The sequencing analysis of the examined samples revealed $99 \%$ identity with some other species from the same family. Therefore, the choice of reliable genetic markers for species identification would assure the sequence assignment and the phylogenetic results (Abouelhassan et al., 2019). In addition, the primers should be designed to be more specific with no cross-reaction with other trematodes (Chontananarth et al., 2018).

Difficulties of getting sufficient and pure DNA template from minute helminths limits the application of molecular methods for species identification. Several commercial kits have been tested for DNA extraction from minute helminths and their eggs (Doyle et al., 2019). However, these kits are relatively expensive, and some of the DNA may be lost during the extraction process. Here, the Hotshot method was modified for the DNA extraction from minute helminths and encysted metacercariae, and compared the results with the commercial DNA extraction kit. As reported by Meeker et al. (2018), this method was used for DNA extraction from several zebrafish tissues especially samples that are difficult to extract such as the sperm. DNA extracted by this method is stable at $4^{\circ} \mathrm{C}$ for at least 3 months, and can be stored at $-20^{\circ} \mathrm{C}$ for a longer time.

\section{CONCLUSION}

In conclusion, molecular identification with better genetic marker selection will improve the identification of the parasite species and their larval stages. The Hotshot method is rapid, easy, cheap, simple with a few steps, and does not require special reagents or enzymes. In addition, no DNA is lost during the extraction process because nothing is removed from the extraction tubes. This method can be tested for DNA extraction from other minute parasites, especially for applications that require DNA of good quality and yield such as whole-genome sequencing.

\section{REFERENCES}

Abou-Eisha M.; Saleh R.E.; Fadel H. M.; Youssef E. M. and Helmy Y. H. (2008). Role of freshwater fishes in the epidemiology of some zoonotic trematodes in Ismailia province. SCVJ, XIII (2)

Abouelhassan E.; ElGawady H.; AbdelAal A.; El-Gayar A. and Gassent M. (2019). Comparison of some Molecular Markers for Tick Species Identification. J Arthropod Borne Dis. 13(2):153-164 
Abou Zaid A.A.; Bazh E.K.; Desouky A.Y. and Abo-Rawash A.A. (2018). Metazoan parasite fauna of wild sea bass; Dicentrarchus labrax (Linnaeus, 1758) in Egypt. Life Sci. J. 2018;15(6)

Arya L.K.; Rathinam S.R.; Lalitha P., Kim U.R. and Ghatani S. (2016). Trematode fluke Procerovum varium as cause of ocular inflammation in children, South India. Emerg. Infect. Dis., 22: 192-200

Borgsteede F.H. (1996). The effect of parasites on wildlife. 18 Suppl 3:S138-40

Chontananarth T.; Sothorn A. S.;Tejangkura T. (2018). The rapid detection method by polymerase chain reaction for minute intestinal trematodes: Haplorchis taichui in intermediate snail hosts based on 18s ribosomal DNA. J Parasit Dis. 42: 423-432

Chuboon S. and Chalobol W. (2009). Molecular identification of larval trematode in intermediate hosts from chiang mai,Thailand, Southeast Asian J Trop Med Public Health. 40(6):1216-20

\section{Doyle S.R.; Sankaranarayanan G.; Allan F., Berger D.; Jimenez Castro P.D.;} Collins J.B.; Crellen T; Duque-Correa M.A., Ellis P.; Jaleta T.G. and Laing R. (2019). Evaluation of DNA extraction methods on individual helminth egg and larval stages for whole-genome sequencing. Frontiers in Genetics, 10, p.826

Fadel H. M.; El- Lamie M. M. and Sallam N. H. (2019). Surveillance of parasitic diseases of zoonotic importance in fishermen, some fish and shellfish species. J Anim and Vet. Advances, 18 (6), 175-186

Johnson M.; Zaretskaya I.; Raytselis Y.; Merezhuk Y; McGinnis S. and Madden T.L. (2008). NCBI BLAST: a better web interface. Nucleic Acids Research, 36, (20) W5-W9.

Gasser R.B.; Chilton N. B.; Herve H .and Beveridge I. (1993). Rapid sequencing of rDNA from single worms and eggs of parasitic helminths Nucleic Acids Res., 21, (10)2525-2526.

Geracia S.N; Johnstonb J.S; Robinsona J.P.; Wikelc S. K. and Hilla C A (2007). Variation in genome size of argasid and ixodid ticks. Insect Biochem. and Molecular Bio. 37,399-408

Georgi J.R. and Georgi M.E. (1992). Canine Clincal Parasitology .Lea and Febiger; Philadelphia, London

Keiser J. and Utzinger J.(2009). Food-borne trematodiases. Clin. Microbiol. Rev., 22: 466-483 
Kumar S.; Stecher G.; Li M.; Knyaz C. and Tamura K. (2018). MEGA X: Molecular Evolutionary Genetics Analysis across computing platforms. Molecular Biol.and Evol. 35:1547-1549

Mahdy O.A.; Essa M.A. and El-Easa M. (1995). Parasitological and pathological studies in Tilapia sp. from Manzala, Egypt. J. Comp. Pathol. Clin. Patho., 8: 131-145.

Meeker N.D.; Hutchinson S.A.; Ho L. and Trede N.S. (2007). Method for isolation of PCR-ready genomic DNA from zebra fish tissues. Biotechniques, 43(5): 610-614.

Mohamed I.B. (1996). Pathological changes in some fish eating mammals as a result of consumption of fish infested with encysted metacercariae. Ph.D.Thesis, (Pathology), Fac. Vet. Med, Cairo Univ.

Morishita K.; Komiya K. and Matsubayashi H. (1965). Progress of Medical Parasitology in Japan. Meguro parasitological museum, Tokyo, Japan. 2:88-167

Schaperclaus W.; Kulow H. and Schreckenbach K.(1992) Fish diseases. A.A. Balkema, Rotterdam, the Netherlands. Science, 142: 676-678

Tamura K. and Nei M. (1993). Estimation of the number of nucleotide substitutions in the control region of mitochondrial DNA in humans and chimpanzees. Molecular Biolo. and Evol. 10:512-526

World Health Organization (1995). Control of food borne trematode infections. WHO technical report 849. WHO technical report series. Geneva, Switzerland, pp: 1-159 